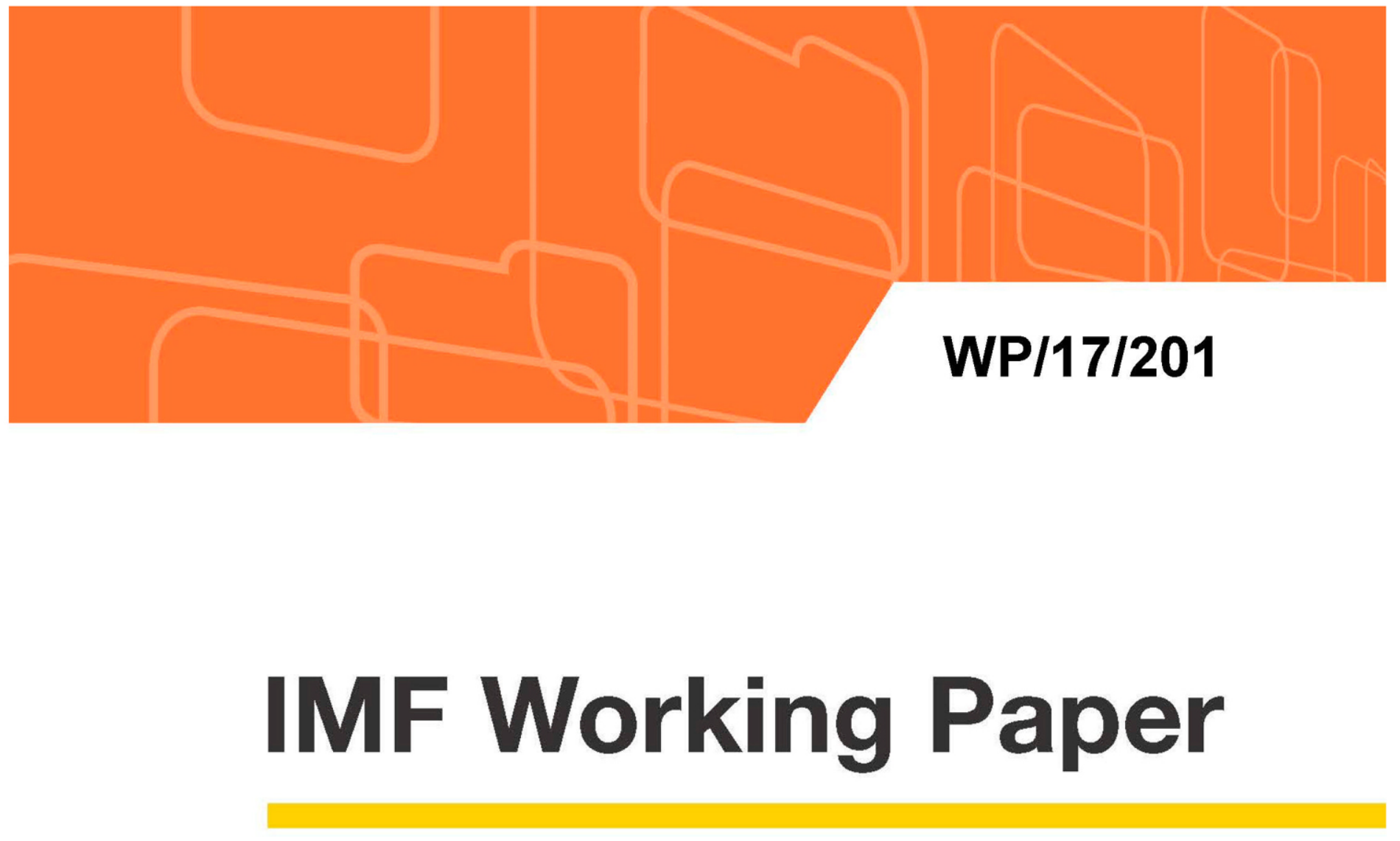

What prevents a real business cycle model from matching the U.S. data? Decomposing the labor wedge

by Dmitry Plotnikov

IMF Working Papers describe research in progress by the author(s) and are published to elicit comments and to encourage debate. The views expressed in IMF Working Papers are those of the author(s) and do not necessarily represent the views of the IMF, its Executive Board, or IMF management. 


\section{WP/17/201}

\section{IMF Working Paper}

What prevents a real business cycle model from matching the U.S. data? Decomposing the labor wedge

by Dmitry Plotnikov

IMF Working Papers describe research in progress by the author(s) and are published to elicit comments and to encourage debate. The views expressed in IMF Working Papers are those of the author(s) and do not necessarily represent the views of the IMF, its Executive Board, or IMF management. 
Western Hemisphere Department

\title{
What prevents a real business cycle model from matching the U.S. data? Decomposing the labor wedge
}

\section{Prepared by Dmitry Plotnikov ${ }^{1}$}

Authorized for distribution by Lorenzo Figliuoli

June 2017

\section{IMF Working Papers describe research in progress by the author(s) and are published to} elicit comments and to encourage debate. The views expressed in IMF Working Papers are those of the author(s) and do not necessarily represent the views of the IMF, its Executive Board, or IMF management.

\begin{abstract}
I carry out a business cycle accounting exercise (Chari, Kehoe and McGrattan, 2007) on the U.S. data measured in wage units (Farmer (2010)) for the entire postwar period. In contrast to a conventional approach, this approach preserves common medium-term business cycle fluctuations in GDP, its components and the unemployment rate. Additionally, it facilitates decomposition of the labor wedge into the labor supply and the labor demand wedges. Using this business cycle accounting methodology, I find that in the transformed data, most movements in GDP are accounted for by the labor supply wedge. Therefore, I reverse a key finding of the real business cycle literature which asserts that $70 \%$ or more of economic fluctuations can be explained by TFP shocks. In other words, the real business cycle model fits the data badly because the assumption that households are on their labor supply equation is flawed. This failure is masked by data that has been filtered with a conventional approach that removes fluctuations at medium frequencies. My findings are consistent with the literature on incomplete labor markets.
\end{abstract}

JEL Classification Numbers: E31, E32, E37, Q41, Q43

Keywords: Unemployment, business cycles, labor wedge

Author's E-Mail Address: dplotnikov@imf.org

\footnotetext{
${ }^{1}$ I wish to to thank Andrew Atkeson, Lee Ohanian, Roberto Garcia-Saltos and Aaron Tornell for their detailed comments as well as participants of the Monetary Economics Proseminar at UCLA and the ICD seminar for their helpful feedback. I am especially thankful to Roger Farmer for his time and invaluable advice. All errors are my own.
} 
Contents

Page

I. Introduction $\ldots \ldots \ldots \ldots \ldots$

II. Removing the Time Trend Using Wage Units . . . . . . . . . . . . . $\underline{6}$

III. A Prototype Economy . . . . . . . . . . . . . . . . . . . 10

IV. Accounting Procedure: Evaluating the RBC Model . . . . . . . . . . . . . 12

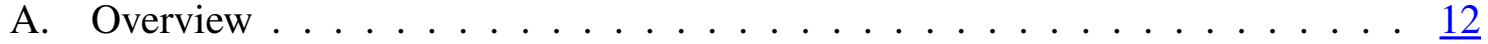

B. The Accounting Procedure Using the Prototype Economy . . . . . . . . . 13

C. Priors ............................... 16

D. Parameter Estimates . . . . . . . . . . . . . . . . . . 17

E. Realized Wedges . . . . . . . . . . . . . . . . . 18

F. The Contribution of Each Wedge to the Data Fluctuations . . . . . . . . 23

V. Discussion of the Results .................... . . 28

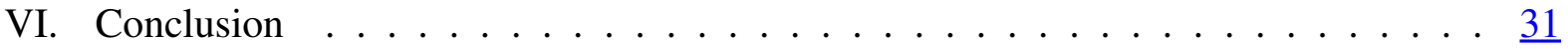

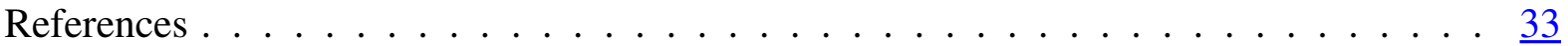

List of Tables

1. Prior distributions of parameters of the model . . . . . . . . . . 16

2. Estimates of all of the parameters on the quarterly data from 1948:1 to 2011:4. . . 17

3. Properties of the wedges 1948:1-2011:4 . . . . . . . . . . . . 21

4. Share of variation in output and unemployment explained by different wedges,

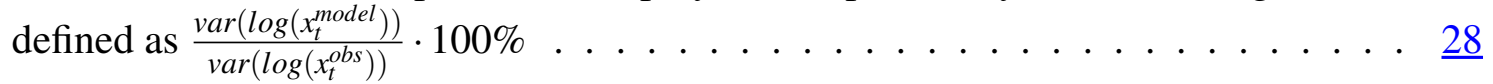

\section{List of Figures}

1. Civilian unemployment rate (percent, left scale, inverted) and GDP in wage units (right scale). Quarterly data 1948:1 - 2011:4. Shaded areas are NBER recession dates. . . . . . . . . . . . . . . . . . .

2. Posterior distributions. Grey lines represent prior densities. Dark lines represent posterior densities. Dashed lines are estimated modes of the posterior densities. SE stands for standard error. . . . . . . . . . . . . . . . . . 18

3. Realized wedge series as an outcome of the estimation procedure for the entire postwar period. Grey areas indicate NBER recessions. . . . . . . . . . . . . . 19

4. Realized wedge series as an outcome of the estimation procedure for the period 2000:1-2011:4. Grey areas indicate NBER recessions. . . . . . . . . . . . . . 20

5. Annualized percent change in TFP: data vs. model. For definitions see equations (29) and (30). . . . . . . . . . . . . . . . . . . . . . 22

6. Investment wedge only economy. Dashed lines represent the series implied by the model. Solid lines represent the actual series. 
7. Efficiency wedge only economy. Dashed lines represent the series implied by the model. Solid lines represent the actual series. . . . . . . . . . . . . 25

8. Labor demand wedge only economy. Dashed lines represent the series implied by the model. Solid lines represent the actual series. . . . . . . . . . . . . . 26 26

9. Labor supply wedge only economy. Dashed lines represent the series implied by the model. Solid lines represent the actual series.. . . . . . . . . . . . 27

10. U.S. GDP detrended in three different ways. . . . . . . . . . . . . . . . 29

11. Components of the standard measure of hours worked. . . . . . . . . . . . $\underline{30}$

12. Normalized series of hours worked (left scale) and the employment rate (right scale) $\underline{30}$ 


\section{INTRODUCTION}

This paper studies which features a general equilibrium model should have to explain the business cycle dynamics both before and after the Great Recession of 2008. Specifically, both output and unemployment returned to to pre-recession levels of output and employment much later than in the previous postwar U.S. recessions. The U.S. unemployment rate has remained above $8 \%$ for more than 11 quarters. Real U.S. GDP dropped more than $2 \%$ during the crisis and in contrast to previous postwar recessions did not jump back to the pre-recession trend. The two main questions of this paper are the following. First, if the dynamics that we have observed are part of the business cycle, can they be reconciled within a standard framework together with the rest of the postwar data? Second, if not, what are the required features of a successful model to explain observed fluctuations that are absent in the standard model?

Several researchers argued that the highly persistent output and employment post-2008 dynamics imply a loss in potential output and, correspondingly, an increase in the equilibrium unemployment rate (Benes and others (2010), IMF (2009), Ball (2014), Haltmaier (2012) among others). To extract a measure of potential output these studies generally rely on a univariate filter or a multivariate filter with parametric equations. In this approach, potential output is essentially a residual that satisfies the specified functional equations given the observed data in the long-run and the model explains deviations of unemployment from the equilibrium level, but not the actual level. The equilibrium unemployment rate in this approach is linked with the potential output level, which is efficient. In this paper I remove the trend from output non-parametrically based on Kaldor facts, obtaining series that do not grow over time. Similarly, I do not detrend the unemployment rate aiming to see whether a standard model can explain actual employment levels and not deviations from a trend.

Based on the persistent behavior of the unemployment rate after 2008 and its similarity to the Great Depression several researchers have begun to consider models with multiple equilibria (see Kaplan and Menzio (2012), Heathcote and Perri (2012), Farmer (2012), Kashiwagi (2012), Cowen (2012), Guerrazzi (2010) and Basu (2009) among others.) For example, Farmer (2012) argues in favor of models with multiple steady state equilibria, with only one of them efficient. He claims that the reason why unemployment has not swiftly returned to its pre-recession level of $5 \%$ is because the economy switched to a new, inefficient steady state equilibrium with a higher unemployment rate and the lower level of output. He also argues that the standard real business cycle (RBC) model is unable to match these unemployment and GDP dynamics for the same reasons that the Great Depression is hard to reconcile within such framework. Since a standard RBC model has a unique and efficient steady state equilib- 
rium, for plausible parameter values it implies that the economy quickly returns to its steady state.

Even though there is agreement in the literature (see, for example Cole and Ohanian (2004)) that an RBC model cannot explain the persistence of the unemployment rate during the Great Depression of 1929, it has not been tested on the recent data. First, the increase in the unemployment rate is much smaller (from 5\% to above $8 \%$ for the current recession and from $2 \%$ to $25 \%$ for the Great Depression). Second, in the current recession productivity decreased significantly, a feature that is potentially consistent with conventional explanations.

In this paper I conduct an empirical exercise to analyze which assumptions, if any, prevent a standard model from matching the persistence of the unemployment rate for the current recession and the entire postwar period. I proceed as follows. I deflate nominal GDP and its components by a series of money wages. I verify that the resulting series do not have a time trend. I call this detrended series "GDP in wage units". I show that GDP in wage units is twice as volatile as real GDP detrended by a more conventional approach such as the HP filter. The reason is that the HP filter removes medium term fluctuations that are an important component of business cycles. ${ }^{1}$ Note that preserving medium term comovements in the data is directly related to the questions I answer in the paper: I am interested if the standard model can explain high level of unemployment (low levels of GDP) for a long time period, not its deviations from the HP trend.

I establish that GDP in wage units is highly correlated with unemployment. Since unemployment is a measure of underutilization of resources, the medium term movements in GDP that are removed by the filter are, arguably, an important determinant of welfare fluctuations over the business cycle.

Next, I carry out a business cycle accounting exercise (as in Chari, Kehoe, and McGrattan (2007)) on the data detrended in this new way. First, I describe the benchmark RBC model (see Section 3) and introduce wedges in the model's equations that do not hold exactly in the data. Second, I estimate this model using Bayesian techniques and obtain smoothed values for all wedges (see Section 4 for details).

By constructing the wage series I am able to decompose the labor wedge - the residual in the equation describing a labor market equilibrium - into the labor supply and the labor demand wedges. This means I evaluate the model's predictions about labor supply and labor demand

\footnotetext{
${ }^{1}$ A more conventional, but mechanical, band-pass filter(Baxter and King (1999)), preserves fluctuations at medium frequencies but potentially extracts different trends from different series.
} 
independently. This contrasts with the conventional approach in the real business cycle literature in which wages are eliminated from the equilibrium model equations.

Using the methodology of Chari, Kehoe, and McGrattan (2007), later CKM, I reverse a key finding of the real business cycle literature which asserts that $70 \%$ or more of economic fluctuations can be explained by TFP shocks. In contrast, in the transformed data, most movements in GDP are accounted for the labor supply wedge. In other words, the real business cycle model fits the data badly because the assumption that households are on their labor supply equation is flawed. Specifically, the observed consumption, wage and unemployment data is away from the optimal solution implied by the household utility maximization. This, in turn, supports the view that high unemployment observed after the Great Recession was inefficient.

My findings are different from the real business literature because of the way I detrend the data. A conventional univariate approach - the HP or a band-pass filter - removes a significant part of the common business cycle fluctuations from the series among other issues (see, for example, Canova (2014)).

My results empirically consistent with abandonment of the standard labor-leisure condition as suggested in the literature on incomplete labor markets (see Farmer (2010); Farmer and Plotnikov (2012); Kashiwagi (2012); Kocherlakota (2012); Miao, Wang, and Xu (2012)) They also support introduction of multiple equilibria as a way of dealing with the inability of a standard model to fit medium-term fluctuations.

Clearly, policy implications from my analysis are very different from the standard approach. In the standard approach potential output and the corresponding equilibrium unemployment rate are efficient outcomes that are supply determined. If a proportion of a decline in what we think is potential output and corresponding increase in unemployment is a switch to a different, inefficient and partially demand-determined equilibrium, demand-stimulating monetary and fiscal actions are justified in contrast with the standard approach.

\section{Removing the Time Trend Using Wage Units}

This section outlines the detrending procedure I use in this paper. ${ }^{2}$ A key advantage of this procedure is that it preserves medium and long-term fluctuations across different macroeconomic series and has economic intuition based on Kaldor's facts. This contrasts with a more

\footnotetext{
${ }^{2}$ This procedure was developed by Farmer (2010). See this paper for further details
} 
conventional, but mechanical, band-pass filter (Baxter and King (1999)), which extracts different trends from different series.

The intuition behind the detrending procedure is simple. To remove inflation and the trend in total factor productivity (TFP) from nominal macroeconomic variables, one can divide the variable of interest by nominal wage. ${ }^{3}$ Following Farmer (2010) I define the nominal wage to be: 4

$$
W_{t}=\frac{(\text { compensationto employees })_{t}}{(\text { numberof full-time equivalent employees })_{t}}
$$

Compensation to employees is a better measure of the wage than gross earnings alone because it includes all monetary benefits (not just salary) paid to employees. Using the constructed series of wages, $W_{t}$, GDP in wage units is defined as

$$
Z_{t}=\frac{Y_{t}}{W_{t}} \cdot \frac{1}{N_{t}}
$$

where $Y_{t}$ is nominal U.S. GDP and $N_{t}$ is the civilian labor force in period t. ${ }^{5}$ While the ratio of total GDP to the nominal wage $\frac{Y_{t}}{W_{t}}$ should now be free of inflation and productivity trends, it still grows because the number of working people increases with time. For this reason I further divide this ratio by a measure of civilian labor force $N_{t} \cdot{ }^{6}$ The term $Z_{t}$ represents GDP deflated by wage and expressed in per-capita terms.

The output in wage units, $Z_{t}$, can be interpreted in the following way. First, let $b_{t}$ be the share of labor income in the total nominal output $Y_{t}$, and let $L_{t}$ denote the number of full-time equivalent employees (FTE) used in production of the output. Then, by the definition of the share of labor income,

\footnotetext{
${ }^{3}$ By contrast, deflating by price alone removes only inflation and requires further detrending, e.g. using the HPfilter.

${ }^{4}$ Both series are available from BEA website on the annual basis from 1929 to 2011 . I linearly interpolated resulting wage series to obtain quarterly data. Since the original series is very smooth, the error associated with interpolation should not be large.

${ }^{5}$ This definition of GDP in wage units is robust with respect to different measures of the labor force: total vs. civilian. The difference between the two measures of the labor force during the entire postwar period does not exceed $2 \%$.This difference does not affect the resulting series for GDP in wage units.

${ }^{6}$ While it might be intuitive to divide by population to express GDP in per capita terms, I divide by the labor force $\left(N_{t}\right)$. The model ignores fluctuations in employment due to people entering and leaving the labor force. In contrast, the standard RBC literature ignores the other key reason for fluctuations in employment: individuals in the labor force receiving and leaving jobs. See section 5 for more details.
} 


$$
b_{t} Y_{t}=W_{t} L_{t}
$$

The RHS of Equation ((3)) is the compensation of FTE in dollars. The LHS of this equation is total nominal GDP multiplied by the (potentially time-varying) share of the labor income. Dividing both sides of Equation ((3)) by the civilian labor force $N_{t}$ and the constructed series of nominal wages $W_{t}$, Equation ((3)) implies

$$
\frac{Y_{t}}{W_{t}} \cdot \frac{1}{N_{t}}=\frac{1}{b_{t}} \cdot \frac{L_{t}}{N_{t}}
$$

The LHS of the Equation (4) is equal to $Z_{t}$, GDP in wage units, as defined in Equation ((2)). The ratio $\frac{L_{t}}{N_{t}}$ on the RHS of Equation (4) is the employment rate in the economy and the unemployment rate is $u_{t}=\frac{N_{t}-L_{t}}{N_{t}}=1-\frac{L_{t}}{N_{t}}$. Combining this definition with Equation (4) leads to the following expression:

$$
Z_{t}=\frac{1}{b_{t}}\left(1-u_{t}\right)
$$

Equation (5) implies that GDP in wage units is equal to the product of the inverse of the labor share and the employment rate. If the labor income share were constant, GDP in wage units would have been proportional to the employment rate. In the data, the constructed series of GDP in wage units $Z_{t}$ and the civilian employment rate reported by Bureau of Labor Statistics (BLS) - defined as one minus the unemployment rate - for the quarterly postwar data are highly correlated, but not exactly proportional. Statistically, the correlation between these series is -0.88 . Figure 1 presents these series graphically. The constructed series of GDP in wage units is on the right axis and the unemployment rate is on the inverted left axis.

Why are the series on Figure 1 different? The RHS of Equation (5) suggests two possible reasons. First, the unemployment rate reported by BLS is different from the unemployment rate defined above. Because BLS does not distinguish between part-time and full-time workers and counts both of them as employed, the unemployment rate defined above is larger than the unemployment rate reported by BLS. ${ }^{7}$ In the paper I use the series reported by BLS because it is more conventional and widely used in the literature. ${ }^{8}$ Second, the share of labor income

\footnotetext{
${ }^{7}$ For example, consider a part-time employee working $50 \%$ of the full-time employment. In the number of FTE, $L_{t}$, this employee is counted as $\frac{1}{2}$, whereas BLS counts him as 1 in the number of people employed. Nevertheless, correlation between these two series is very high - 0.93 .

${ }^{8}$ Correlation between these two series is close to one -0.93 .
} 
in the total output $b_{t}$ is not constant and in fact counter-cyclical over time (IMF (2017), Choi and Rios-Rull (2009); Rios-Rull and Santaeulalia-Llopis (2010)). In particular, the divergence of two series after 2009 can be potentially attributed to a fall in the labor share. ${ }^{9}$

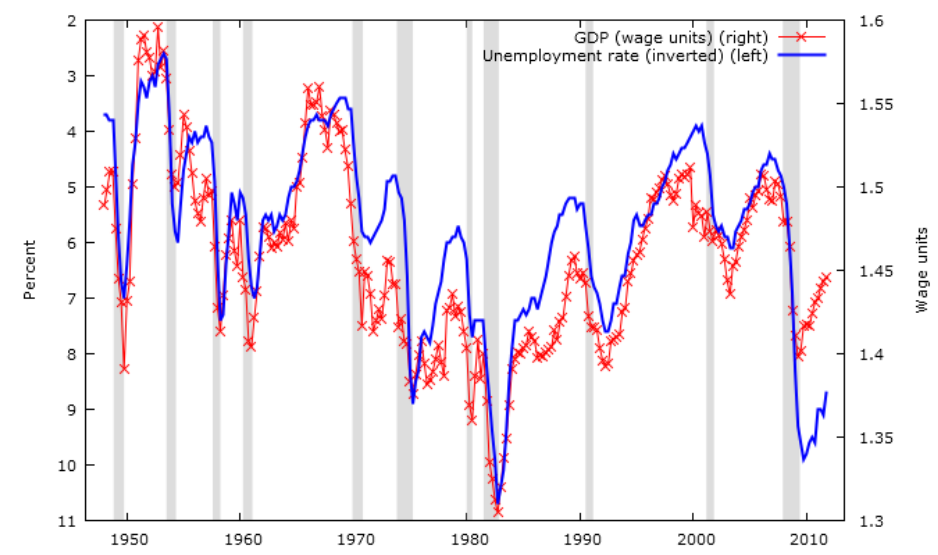

Figure 1. Civilian unemployment rate (percent, left scale, inverted) and GDP in wage units (right scale). Quarterly data 1948:1 - 2011:4. Shaded areas are NBER recession dates.

Next I detrend different components of GDP in a similar way. Using data from the NIPA tables, I define nominal investment $I_{t}$ to be equal to the sum of nominal private and government investment. Then, using the national accounts identity for nominal GDP, I define nominal consumption to be

$$
C_{t}=Y_{t}-I_{t}
$$

In other words, $C_{t}$ contains nominal private consumption, government consumption and net exports. Similarly to the definition of GDP in wage units, I define investment in wage units , $I_{t}^{w}$, and consumption in wage units, $C_{t}^{w}$ to be

$$
I_{t}^{w}=\frac{I_{t}}{W_{t}} \cdot \frac{1}{N_{t}} \quad C_{t}^{w}=\frac{C_{t}}{W_{t}} \cdot \frac{1}{N_{t}}
$$

Equation (7) states that $C_{t}^{w}$ and $I_{t}^{w}$ represent consumption and investment deflated by the nominal wage and expressed in per-capita terms. These series have two important properties.

\footnotetext{
${ }^{9}$ The decrease in the labor share of total income was pointed out by several researchers in the literature. See, for example, Gomme and Rupert (2004); Jacobson and Occhino (2012)
} 
First, it follows from Equations (2), (6) and (7) that the national accounts identity still holds for series in wage units:

$$
Z_{t}=C_{t}^{w}+I_{t}^{w}
$$

Most importantly, since all of the series were detrended using the same nominal wage series, $W_{t}$ and the civilian labor force $N_{t}$, medium- and long-term comovements among GDP, consumption investment and unemployment are preserved. In contrast, the standard mechanical HP-filtering procedure eliminates medium- and long-term comovements because it removes potentially different trends from these series.

\section{A Prototype EConomy}

In this section I describe a RBC model that I later use in the accounting procedure. I choose functional forms that are similar to the ones used in CKM as the "prototype economy" except that I interpret hours worked by individuals as the employment rate. I picked this version of the model to make my quantitative results comparable to the ones obtained in CKM. See section 5 for the standard alternative specification.

There is one infinitely-lived household that maximizes expected discounted life-time utility of its members. At any given moment of time $t$, a share $l_{t} \in(0,1)$ of members of the household are employed and a share $1-l_{t}$ are not. The household head derives utility from real consumption $c_{t}$ per household member and the share of its members who do not work $1-l_{t}$. This setup implicitly assumes that the labor force in the economy - the number of members of the household - is normalized to unity and $l_{t}$ corresponds to the employment rate. For the same reasons, $c_{t}$ corresponds to the real consumption per member of the labor force. The oneperiod utility function of the household's head is

$$
u\left(c_{t}, l_{t}\right)=\log \left(c_{t}\right)+\psi \cdot \log \left(1-l_{t}\right)
$$

Each working member of the household earns real wage $w_{t}$ per period so that the labor income of the household is $w_{t} l_{t}$. The household can also accumulate capital $k_{t}$ that it rents out to firms for the real rental rate $r_{t}$ per period. This leads to the standard budget constraint: 


$$
c_{t}+i_{t}=r_{t} k_{t}+w_{t} l_{t}
$$

where $i_{t}$ is the investment in period $t$ per member of the labor force. Capital depreciates with the rate $\delta$ per period and evolves according to the following expression:

$$
k_{t+1}=i_{t}+(1-\delta) k_{t}
$$

The household discounts future utility with discount factor $\beta$. It takes wages and rental rates as given and maximizes $E_{t}\left[\sum_{s=t}^{\infty} \beta^{s-t} u\left(c_{s}, l_{s}\right)\right]$ subject to equations (9) and (10). The solution to the household's maximization problem can be summarized by the following Euler and labor supply equations:

$$
\begin{gathered}
\frac{1}{c_{t}}=\beta E_{t}\left[\frac{1}{c_{t+1}}\left(1-\delta+r_{t+1}\right)\right] \\
\psi c_{t} \frac{1}{1-l_{t}}=w_{t}
\end{gathered}
$$

Consumption and investment goods are perfect substitutes in production and produced by firms using the technology:

$$
y_{t}=A_{t} k_{t}^{\alpha} l_{t}^{1-\alpha}
$$

where $1-\alpha$ is labor's share of income and $y_{t}$ is the real output per member of the labor force. The term $A_{t}$ represents the aggregate level of technology. Firms maximize profit by renting capital and hiring labor in perfectly competitive markets. They take wages and rental rates as given. The first order conditions for the maximization problem of the firm are standard:

$$
\begin{gathered}
r_{t}=\frac{\alpha y_{t}}{k_{t}} \\
w_{t}=\frac{(1-\alpha) y_{t}}{l_{t}}
\end{gathered}
$$


The general equilibrium of the model is described by the system of equations (9) - (15). Combining Equations (9), (11) and (14) leads to the standard national accounts identity

$$
c_{t}+i_{t}=y_{t}
$$

and the Euler equation

$$
\frac{1}{c_{t}}=\beta E_{t}\left[\frac{1}{c_{t+1}}\left(1-\delta+\frac{\alpha y_{t+1}}{k_{t+1}}\right)\right]
$$

The final set of equations to be used in the accounting procedure in the next section is summarized by 6 equations: the capital accumulation equation (10), the labor supply equation (12), the production function (13), the labor demand equation (15), the national accounts identity (16) and the forward-looking Euler equation (17). Together these equations determine the vector of variables

$$
x_{t}=\left[c_{t}, y_{t}, i_{t}, k_{t+1}, w_{t}, l_{t}\right]
$$

\section{Accounting Procedure: Evaluating the RBC Model}

\section{A. Overview}

The objective of the accounting procedure is to evaluate how well the RBC model describes fluctuations in the data. The procedure I use is identical to the accounting procedure introduced in CKM for the postwar quarterly data with three important differences. First, the data I use preserves medium and long-term comovements between GDP and its components and the unemployment rate; the CKM paper uses HP-filtered data. Using series in wage units facilitates decomposition of the labor wedge into the labor demand and the labor supply wedges. Second, I use the unemployment rate data as a measure of employment in the economy; Chari, Kehoe, and McGrattan (2007) use the conventional data on hours worked. ${ }^{10}$ Third, the dataset I use contains the Great Recession of 2008; the dataset used by Chari, Kehoe, and McGrattan (2007) ends in 2003.

\footnotetext{
${ }^{10}$ In Section 5 I discuss how results change if hours worked series is used as a measure of employment.
} 
The intuition behind the accounting procedure is the following. To evaluate a particular equation of the model, I back out the implied residual (or wedge) series that is needed for the equation to hold exactly given the observed series of data. If the equation describes the data well, the residual series should look like white noise with low dispersion. In contrast, a high dispersion and autocorrelation in the residual series indicate problematic equations.

The backed out wedge series for each equation can additionally be interpreted as the required realizations of single or multiple shocks hitting the equation to match the observed series. Using this interpretation, a high dispersion in a wedge series corresponds to highly, and potentially implausibly, volatile shocks needed to explain fluctuations in the data.

Finally, by recovering all of the wedge series one can assess the contribution of each wedge in explaining data fluctuations. To do this one can simply simulate the economy (using estimated policy rules) with all but one realized wedge held constant. A large difference between these simulated series and the corresponding data counterparts indicates low contribution of this particular wedge to the model's ability to explain the data. In contrast, if the simulated series closely follow the data, it implies a high contribution of the selected wedge. Similar experiments can be conducted for any subset of wedges. This exercise identifies the equations that have to be altered (i.e., where shocks need to be introduced) to produce better fit of the model.

\section{B. The Accounting Procedure Using the Prototype Economy}

Following Chari, Kehoe, and McGrattan (2007) I introduce three wedges $\varepsilon^{\text {invest }}, \varepsilon^{L S}$ and $\varepsilon^{\text {eff }}$ (investment, labor supply and efficiency) into three equations of the prototype model (the Euler equation (11), the labor supply (12) and the production function (13) respectively). ${ }^{11}$ The CKM paper shows how these wedges can be interpreted as an investment tax, a labor income tax and an innovation in the technology process.

In addition to these three wedges, I use the constructed series of nominal wages $W_{t}$ to evaluate the fit of the labor supply equation (12) and the labor demand equation (15) separately by

\footnotetext{
${ }^{11}$ Because I am able to decompose government purchases into government consumption and government investment and, additionally, consider net exports to be a part of the consumption series $C_{t}$, I do not have government wedge which is present in the original CKM paper. Excluding net exports from the consumption series and considering it to be an extra wedge does not affect the results of this paper.
} 
adding an extra labor demand wedge $\varepsilon^{L D}$ to Equation (15). ${ }^{12}$ Intuitively, this wedge captures countercyclicality in labor's share of income (Rios-Rull and Santaeulalia-Llopis (2010)). It is possible to introduce this wedge because I observe the unemployment rate, nominal GDP and investment deflated by the nominal wage and expressed per member of the labor force. Model counterparts for these series are series $1-l_{t}, \frac{y_{t}}{w_{t}}$ and $\frac{i_{t}}{w_{t}}$ respectively. ${ }^{13}$

The introduction of wedges transforms the system of equations that describe the general equilibrium of the prototype model to the following equivalent system:

$$
\begin{aligned}
\frac{1}{c_{t}} \exp \left(\varepsilon_{t}^{\text {invest }}\right) & =E_{t}\left[\beta \frac{1}{c_{t+1}}\left((1-\delta) \exp \left(\varepsilon_{t+1}^{\text {invest }}\right)+\frac{\alpha y_{t+1}}{k_{t+1}}\right)\right] \\
w_{t} & =\psi \cdot \exp \left(\varepsilon_{t}^{L S}\right) \cdot c_{t} \frac{1}{1-l_{t}} \\
y_{t} & =A_{t} k_{t}^{\alpha} l_{t}^{1-\alpha} \\
A_{t} & =\exp \left(z_{t}\right) \\
z_{t} & =\rho z_{t-1}+\varepsilon_{t}^{e f f} \\
w_{t} & =\exp \left(\varepsilon_{t}^{L D}\right) \cdot \frac{(1-\alpha) y_{t}}{l_{t}} \\
y_{t} & =c_{t}+i_{t} \\
k_{t+1} & =i_{t}+(1-\delta) k_{t}
\end{aligned}
$$

To back out the realized wedges necessary to match the data, I follow the procedure described in Chari, Kehoe, and McGrattan (2007). First, I estimate a set of parameters of the prototype model using Bayesian maximum likelihood. I log-linearize the system (19)-(26) around the deterministic steady state. Then I solve it using methods developed in Sims (2001). This brings the system to the form

$$
\begin{aligned}
X_{t} & =F \cdot X_{t-1}+G \varepsilon_{t} \\
Y_{t} & =H \cdot X_{t}
\end{aligned}
$$

\footnotetext{
${ }^{12}$ In other words, the labor wedge used in the literature is a difference between labor supply and labor demand wedges, $\varepsilon^{L S}-\varepsilon^{L S}$ (see Equations (15) and (12)). This because the standard RBC literature eliminates real wages from the system (9)-(15) altogether.

${ }^{13}$ Another reason to introduce a wedge in the labor demand equation (15) is to avoid statistical singularity problem. If the aggregate production function is Cobb-Douglas, as I assume in the benchmark model, Equation (15) implies that GDP in wage units has to be proportional to the employment rate. Since in the data these series are not proportional (see Figure 1), the estimation procedure requires a wedge in the labor demand equation (15).
} 
where $X_{t}=\left[\tilde{x}_{t}, z_{t}, E_{t} c_{t+1}, E_{t} y_{t+1}\right]$ is a vector of state variables $\left(x_{t}\right.$ is defined in $((18))$ and a tilde over a variable denotes a $\log$ deviation from the steady state), $Y_{t}=\left[\left(\frac{y_{t}}{w_{t}}\right)^{o b s},\left(\frac{i_{t}}{w_{t}}\right)^{o b s},(1-\right.$ $\left.\left.l_{t}\right)^{o b s}\right]$ is a vector of observables and $\varepsilon_{t}=\left[\varepsilon_{t}^{\text {invest }}, \varepsilon_{t}^{L S}, \varepsilon_{t}^{e f f}, \varepsilon_{t}^{L D}\right]$ represents shocks to the wedges. The index $t$ represents the actual time period and ranges from 1948:1 to 2011:4 the maximum timespan available for the data series considered. Matrices $F, G$ and $H$ are nonlinear functions of underlying parameters of the model.

Equation (27) contains estimated linearized policy functions and the functions that describe how expectations about the future are formed based on the state vector $X_{t-1}$. Equation (28) links the observed series to their model counterparts.

I construct the likelihood for every set of the parameters by treating the first equation as if it were the true data generating process. Since $Y_{t}$ contains fewer variables than $X_{t}$, in order to construct the likelihood for every set of the parameters, I use the Kalman filter algorithm to construct forecasts of all underlying variables $X_{t}$ given observed variables $\left\{Y_{s}\right\}_{s=0}^{t}$.

Then, I combine prior distributions of all parameters with the maximized likelihood function to obtain a posterior likelihood. I compute posterior distributions numerically using the random walk Metropolis-Hastings (MCMC) algorithm. I make 100'000 draws and keep 50'000 of them to ensure independence from the starting point. Further details on the computational procedure can be found in An and Schorfheide (2007).

The second step of the accounting procedure is to use the Kalman filter to obtain smoothed (or realized) wedges. For this, I use the algorithms that are a part of the open source MATLAB package DYNARE (See Adjemian and others (2011)).

Given the estimated series of realized wages and estimated policy functions, I conduct experiments as in Chari, Kehoe, and McGrattan (2007) to evaluate the contribution of each wedge to fit the data. For example, to evaluate contribution of the TFP fluctuations, I consider the efficiency economy where all wedges are constant except the efficiency wedge. To calculate the model predictions for this economy, I feed innovations $\varepsilon_{t}=\left[0,0, \varepsilon_{t}^{\text {eff }}, 0\right]$ (where $\varepsilon_{t}^{\text {eff }}$ are realized TFP shocks) into the estimated policy function ((27)).

The next section describes the numerical results I archived using this accounting procedure. 


\section{Priors}

To obtain posterior estimates of all of the parameters of the model using MCMC algorithm I need to specify priors for all of the parameters of the model. The priors I use are summarized in Table 1.

For capital share $\alpha$, capital depreciation rate $\delta$ and technology persistence $\rho$ I chose prior means to be close to commonly used calibration values. The discount factor $\beta$ is fixed at 0.99. ${ }^{14}$ The choice of 0.99 corresponds to the long-run annual interest rate of $4 \%$. I picked the prior mean for the leisure parameter from the labor supply condition (Equation $((20))$ ) evaluated at the steady state assuming a 5\% long-run unemployment rate.

The prior mean for the standard deviation of the efficiency wedge was picked to be a $2 \%$ deviation from the steady state - the standard calibration value for the technology process. I picked similar prior means for standard deviations of other wages except for the labor wedge. I chose larger value for the labor wedge because I expected it to have higher variance than the other wedges based on the results of CKM paper. I chose prior standard deviations to be as large as possible given the natural limits of the parameters. For parameters with two natural bounds $(0<\alpha, \delta, \rho<1)$ I chose beta distribution, for the leisure parameter $(\psi>0)$ I picked a gamma distribution and for the second moments of wedges I selected an inverse gamma distributions. 15

\begin{tabular}{cccccc}
\hline Parameter & Description & Domain & Distribution & Prior mean & Std.Dev \\
\hline \hline$\alpha$ & Capital share & $(0,1)$ & Beta & 0.33 & 0.15 \\
$\delta$ & Capital depreciation & $(0,1)$ & Beta & 0.03 & 0.015 \\
$\rho$ & Tech. persistence & {$[0,1)$} & Beta & 0.90 & 0.05 \\
$\beta$ & Discount factor & $(0,1)$ & Fixed & 0.99 & - \\
$\psi$ & Leisure parameter & $\mathbb{R}^{+}$ & Gamma & 0.04 & 0.02 \\
$\sigma_{e f f}$ & St.dev. of $\varepsilon^{\text {eff }}$ & $\mathbb{R}^{+}$ & Inv. Gamma & 0.02 & 0.01 \\
$\sigma_{\text {invest }}$ & St.dev. of $\varepsilon^{\text {invest }}$ & $\mathbb{I}^{+}$ & Inv. Gamma & 0.02 & 0.01 \\
$\sigma_{L S}$ & St.dev. of $\varepsilon^{L S}$ & $\mathbb{R}^{+}$ & Inv. Gamma & 0.10 & 0.05 \\
$\sigma_{L D}$ & St.dev. of $\varepsilon^{L D}$ & $\mathbb{R}^{+}$ & Inv. Gamma & 0.02 & 0.01 \\
\hline
\end{tabular}

Table 1. Prior distributions of parameters of the model

\footnotetext{
${ }^{14}$ This parameter is not identified in the data.

${ }^{15}$ In order to have bell-shaped prior distributions with no positive probability mass on either end of the support, the distance between the prior mean and the closest natural limit should not exceed two standard deviations.
} 


\section{Parameter Estimates}

The results of the Bayesian estimation procedure are presented in Table 2. For every parameter I report the prior mean, the posterior mean and the $90 \%$ posterior confidence interval centered around the posterior mode. All of the model parameters have reasonable values. Labor's share of total income is estimated to be $65 \%$ which corresponds to a value often used in the calibration literature. Quarterly capital depreciation of $1.37 \%$ implies about $5.4 \%$ depreciation per year. The long run unemployment rate is estimated to be 5.7\% (from Equation (12) and the estimate for the leisure parameter, $\psi$ ) which is also a standard value used in the literature.

\begin{tabular}{cccc}
\hline Description & Prior mean & Posterior mean & $C I_{90 \%}$ \\
\hline \hline Capital share & 0.33 & 0.3529 & {$[0.3514 ; 0.3546]$} \\
Capital depreciation & 0.03 & 0.0137 & {$[0.0126 ; 0.0147]$} \\
Tech. persistence & 0.90 & 0.9774 & {$[0.9588 ; 0.9958]$} \\
Discount factor & 0.99 & - & - \\
Leisure parameter & 0.04 & 0.0493 & {$[0.0478 ; 0.0509]$} \\
\hline St.dev. of $\varepsilon^{\text {eff }}$ & 0.02 & 0.0093 & {$[0.0074 ; 0.0111]$} \\
St.dev. of $\varepsilon^{\text {invest }}$ & 0.02 & 0.0051 & {$[0.0045 ; 0.0055]$} \\
St.dev. of $\varepsilon^{L S}$ & 0.10 & 0.3091 & {$[0.2846 ; 0.3341]$} \\
St.dev. of $\varepsilon^{L D}$ & 0.02 & 0.0265 & {$[0.0245 ; 0.0283]$} \\
\hline MCMC accept. rate $36 \%$ & 100000 draws & $50000 \mathrm{kept}$ & $\log (L)=1945$ \\
\hline
\end{tabular}

Table 2. Estimates of all of the parameters on the quarterly data from 1948:1 to 2011:4.

The lower half of Table 2 presents estimates of the standard deviation of the realized wedges. Among all of them, the posterior standard deviation of the labor supply wedge, estimated to be 0.31 , stands out. The magnitude of this number relative to the other estimated standard deviations suggests that it explains a lot of the fluctuations at least in one of the observed series. I show later that this intuition is indeed correct.

The posterior standard deviations of the other wedges are much smaller in magnitude. The standard error of the technology wedge is estimated to be $1 \%$, close to its standard calibration value of $2 \%$. Estimated standard deviations for innovations of the investment and labor demand wedges are below $1 \%$. These numbers suggest that the investment wedge does not explain much variation in the data and the variation in labor's share of income (Equation (24)) is relatively small. 
In Figure 2 I plot posterior densities for all of the estimated parameters, together with their prior distributions. This figure shows that all of the parameters are identified. If a parameter were to be weakly or non-identified the difference between its prior and posterior densities would have been small. In contrast, all posterior densities differ significantly from their respective priors indicating strong identification.

The estimates displayed in Table 2 are robust to the choice of prior means. I experimented with different combinations of prior distributions to check robustness of the estimates and obtained insignificantly different results. The maximization routine and MCMC algorithm either produce estimates almost identical to the ones in Table 2 or the routine does not converge at all. For example, varying the prior mean of the standard deviation of the labor wedge over $(0,1)$ interval (keeping other prior distributions the same) does not affect any of the estimates in Table 2.
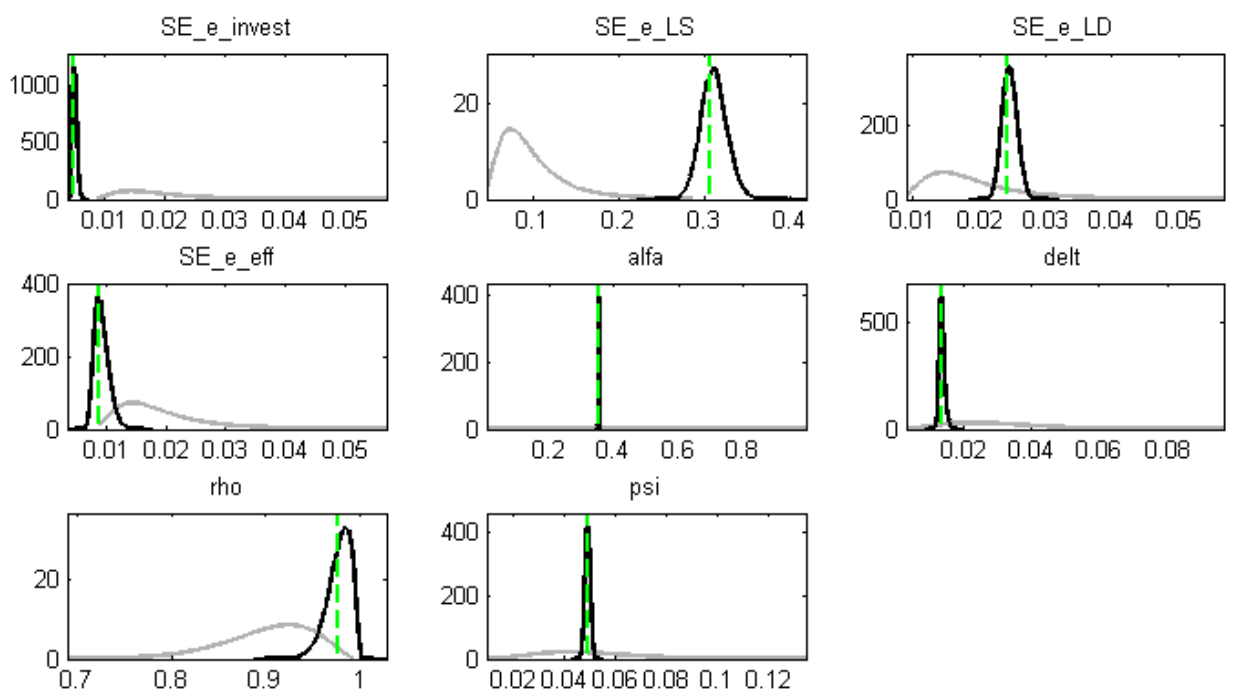

Figure 2. Posterior distributions. Grey lines represent prior densities. Dark lines represent posterior densities. Dashed lines are estimated modes of the posterior densities. SE stands for standard error.

\section{E. Realized Wedges}

Figure 3 presents the realized wedge series graphically. Table 3 summarizes the descriptive statistics of these series. The first half of the table includes individual statistics of each wedge: 
ratio of the variance to log output, and correlation to log output at different lags. The second half of the table presents cross-correlations between wedges at different lags.

Recall that if the prototype model is a good description of the economy, then all four series on Figure 3 should look similar to white noise. In contrast, only the investment wedge series (Figure 3, top right) looks like white noise. Moreover, as the second line of Table 3 shows, white noise is not a bad approximation for this series: investment innovations constitute a very small fraction of the output and are almost uncorrelated with it. This finding indicates that the Euler equation (Equation (19)) holds well in the data. This finding is consistent with CKM paper.
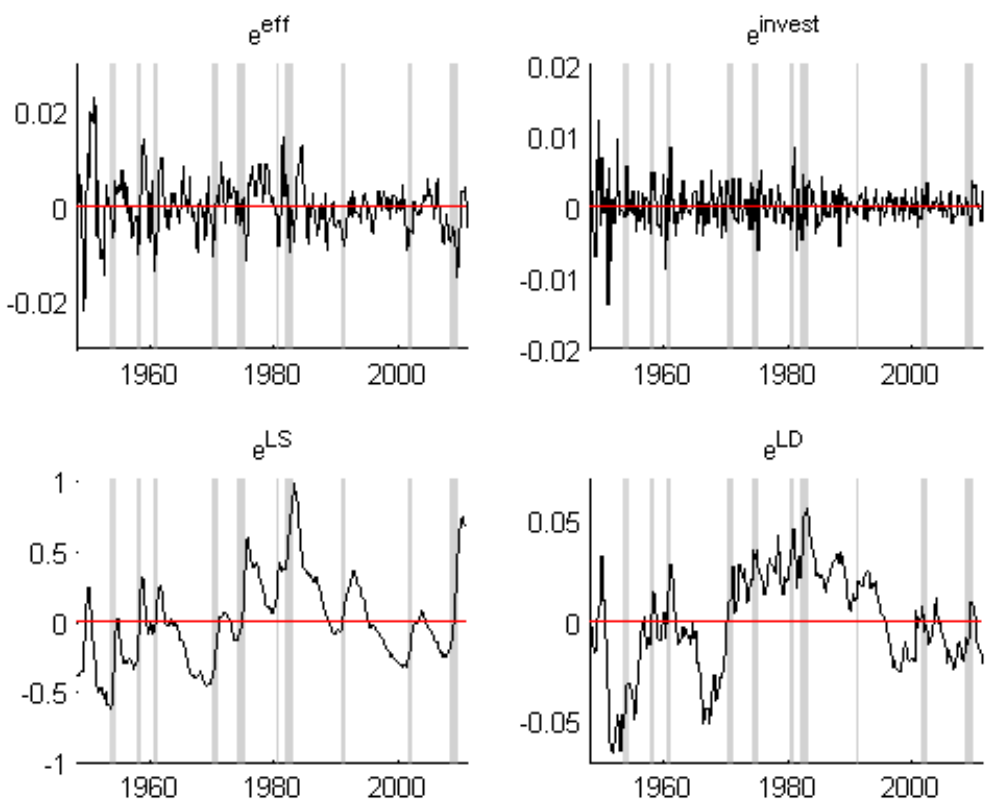

Figure 3. Realized wedge series as an outcome of the estimation procedure for the entire postwar period. Grey areas indicate NBER recessions.

The top left panel of Figure 3 presents realized innovations to total factor productivity. By assumption, this series is the main driving force of economic fluctuations in a real business cycle model. However, as the first line in Table 3 shows, the TFP shocks do not explain data in wage units. This is perhaps not surprising since the TFP shocks are eliminated from GDP when GDP is deflated by the money wage. However, in a standard RBC model one would still expect to see a sharp correlation between TFP and GDP in wage units that operates through 

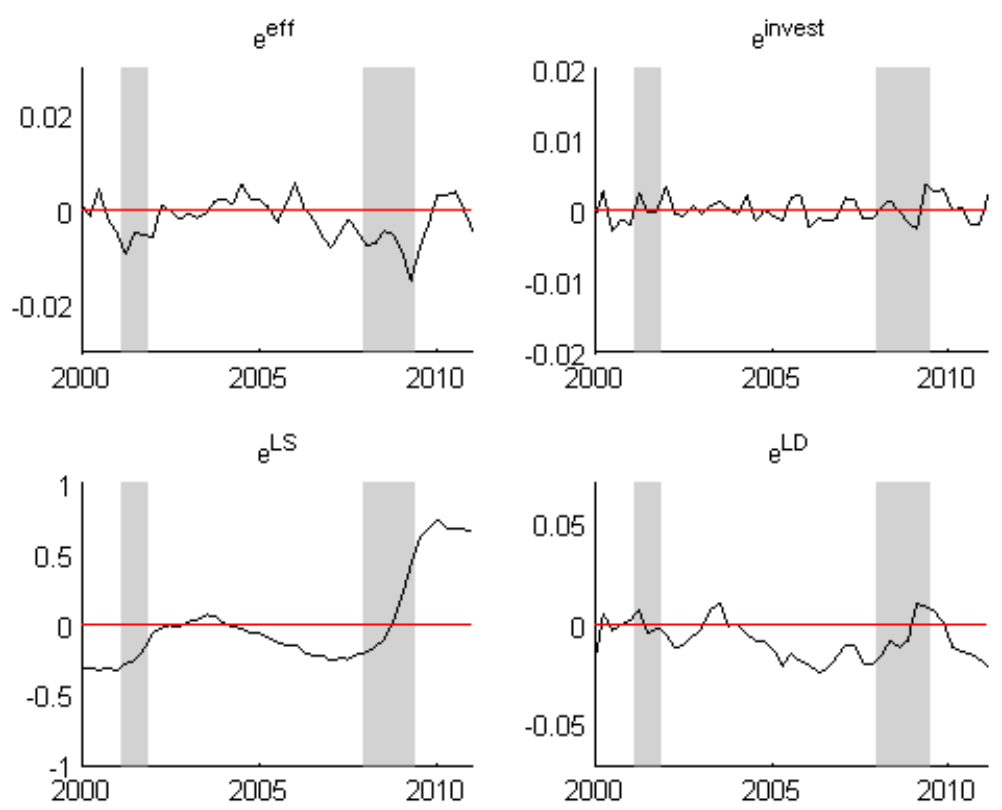

Figure 4. Realized wedge series as an outcome of the estimation procedure for the period 2000:1-2011:4. Grey areas indicate NBER recessions.

an intertemporal substitution mechanism. The low correlation between GDP and the realized TFP shocks indicates that this channel is absent from the data.

Figure 3 also suggests that TFP shocks cannot explain unemployment dynamics. To see this more clearly using the Great Recession as an example, I present the same realized wedge series for the period 2000:1-2011:4 on Figure $4 .{ }^{16}$ The model associates this recession with a large drop in productivity (Figure 4, top left). At the same time the labor supply wedge increases (Figure 4, bottom left) indicating that even such a prolonged sequence of negative TFP shocks is not enough to produce the rise in the unemployment rate observed since 2008. Later, I confirm this hypothesis by simulating an economy that is hit only by the realized TFP innovations with all other wedges kept constant.

Do the implied TFP innovations look realistic? To answer this question I compare implied annualized changes in the logarithm of TFP in the model and in the data. The model counterpart of these series is

$$
400 \cdot\left(\ln \left(T \hat{F} P_{t}^{\text {model }}\right)-\ln \left(T \hat{F} P_{t-1}^{\text {model }}\right)\right)=400 \cdot\left(z_{t}-z_{t-1}\right)
$$

\footnotetext{
${ }^{16}$ Notice that the scale on $y$-axis is different for each wedge series and is normalized according the wedge's variance to better see the dynamics.
} 
A. Summary Statistics

\begin{tabular}{ccccccc}
\hline \multirow{2}{*}{ Wedge } & Variance relative & \multicolumn{5}{c}{ Correlation with log output at lag k= } \\
\cline { 3 - 7 } & to log output & -2 & -1 & 0 & 1 & 2 \\
\hline \hline Efficiency & 0.15 & -0.2893 & -0.2258 & -0.0741 & 0.0080 & 0.0704 \\
Investment & 0.07 & 0.0253 & -0.0548 & -0.1469 & -0.0807 & -0.0630 \\
Labor Supply & 8.15 & -0.8801 & -0.9137 & -0.9136 & -0.8721 & -0.8087 \\
Labor Demand & 0.64 & -0.8248 & -0.8854 & -0.9414 & -0.9203 & -0.8848 \\
\hline
\end{tabular}

$5 \%$ critical value (two-tailed) for correlation coefficients is 0.1225

B. Cross Correlations

\begin{tabular}{cccccc}
\hline & \multicolumn{5}{c}{ Cross Correlation of $\mathrm{X}$ with $\mathrm{Y}$ at lag $\mathrm{k}=$} \\
\cline { 2 - 6 } Wedges $(\mathrm{X}, \mathrm{Y})$ & -2 & -1 & 0 & 1 & 2 \\
\hline \hline Efficiency, Investment & 0.2425 & 0.4758 & -0.5250 & -0.2658 & -0.2369 \\
Efficiency, LS & 0.3128 & 0.2536 & 0.1562 & 0.0448 & -0.0495 \\
Efficiency, LD & 0.2339 & 0.1787 & 0.0217 & -0.0262 & -0.0552 \\
Investment, LS & -0.0279 & 0.0470 & 0.0887 & 0.1072 & 0.0932 \\
Investment, LD & -0.0247 & 0.0482 & 0.1537 & 0.0483 & 0.0304 \\
LS, LD & 0.7540 & 0.7524 & 0.7244 & 0.6833 & 0.6353 \\
\hline 5\% critical value (two-tailed) for correlation coefficients is 0.1225 &
\end{tabular}

Table 3. Properties of the wedges 1948:1-2011:4

where series $z_{t}$ are calculated using implied productivity innovations as

$$
z_{t}=\hat{\rho} z_{t-1}+e_{t}^{e f f}
$$

Note that $z_{t}$ in the model is stationary. In contrast, the TFP series in the data are growing:

$$
T F P_{t}^{d a t a} \equiv\left[\prod_{s=1}^{t}\left(1+g_{s}\right)\right] \times e^{\tilde{z_{t}}}
$$

where $g_{t}$ is the trend component and $\tilde{z_{t}}$ is the cyclical component. This leads to the following expression for the annualized changes in the logarithm of TFP:

$$
400 \cdot\left(\ln \left(T \hat{F} P_{t}^{d a t a}\right)-\ln \left(T \hat{F} P_{t-1}^{d a t a}\right)\right)=400 \cdot \ln \left(1+g_{t}\right)+400 \cdot\left(\tilde{z_{t}}-\tilde{z}_{t-1}\right)
$$

Ideally, one would like to compare the series $z_{t}$ and $\tilde{z}_{t}$. However, the observed series (LHS of equation $((30)))$ is contaminated with a trend component $\ln \left(1+g_{t}\right)$ that is potentially different from period to period. 


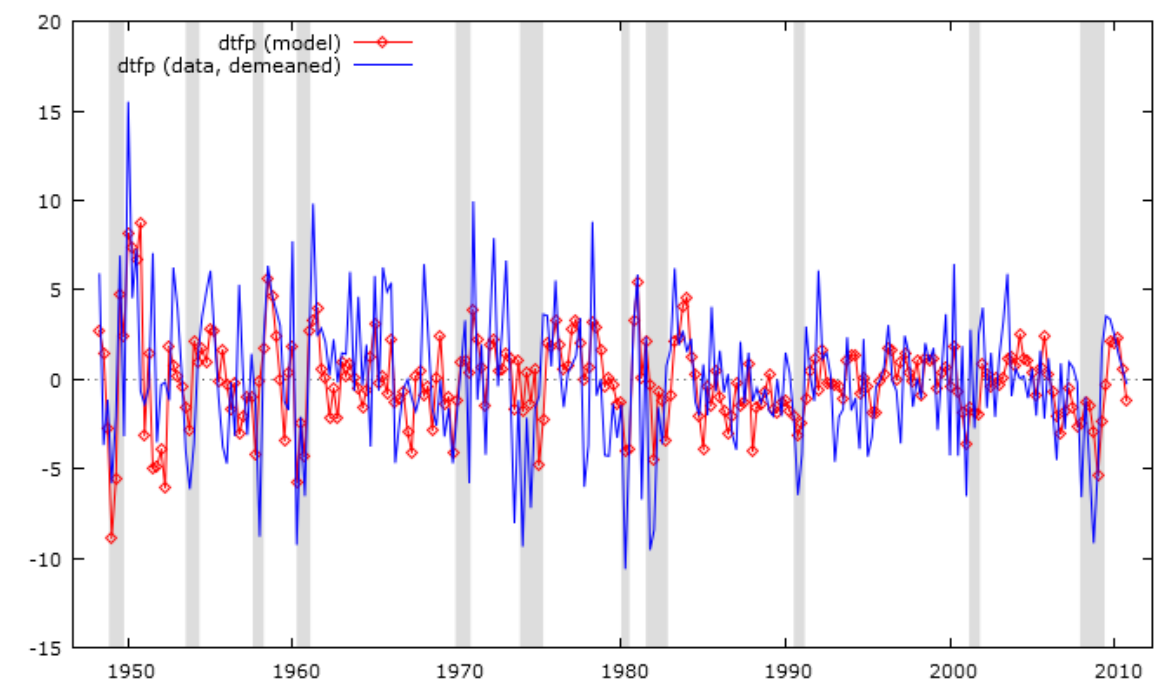

Figure 5. Annualized percent change in TFP: data vs. model. For definitions see equations (29) and (30).

To address this, I plot the demeaned data for annualized change in the logarithm of TFP (Equation (30)) and its model counterpart (Equation (29)) in Figure 5. I use TFP data published on the website of the Federal Reserve Bank of San Francisco. ${ }^{17}$ These two series should coincide if the trend component $g_{t}$ was constant during the whole time period. Since trend component in TFP, $g_{t}$, varies over time, the data series are more volatile than the TFP series implied by the model. Nevertheless the series follow each other closely and exhibit the same pattern for the Great Recession: they both drop below the trend before the recession starts and stay below the trend until the end of the Recession. Figure 5 shows that the model picks up TFP fluctuations that are very close to the empirical estimates, not something else.

The other two wedge series - labor supply and labor demand - do not look like white noise at all. In fact, the labor supply wedge (the bottom left of Figure 3) is highly correlated with the unemployment rate. The labor demand wedge (the bottom right of Figure 3 ) is highly correlated with the output. Both of these observations suggest that these two wedges explain a significant fraction of the variation in the unemployment rate and the output respectively.

The last line in the second half of Table 3 shows why it is important to distinguish between the labor supply and the labor demand wedges. Since the correlation coefficient between these two series is very strong and negative the sum of these two series (which corresponds

\footnotetext{
${ }^{17} \mathrm{http} / / /$ www.frbsf.org/csip/tfp.php
} 
to what Chari, Kehoe, and McGrattan (2007) call the labor wedge) will be less volatile and potentially exhibit less autocorrelation, canceling out effects of each wedge.

\section{F. The Contribution of Each Wedge to the Data Fluctuations}

In this section I assess the contribution of each wedge to the data fluctuations. I consider what Chari, Kehoe, and McGrattan (2007) call one- , two- and three-wedge economies to evaluate the contribution of each wedge. For example, to evaluate the contribution of TFP fluctuations, I consider the efficiency only economy where all wedges are constant except the efficiency wedge. To calculate the model predictions for this economy, I feed innovations $\varepsilon_{t}=\left[0,0, \varepsilon_{t}^{e f f}, 0\right]$ (where $\varepsilon_{t}^{e f f}$ are the realized TFP shocks) into the estimated policy function (27). Recall that if I feed realized innovations of all of the wedges into the estimated policy rules I get back the observed data. Thus, feeding only a subset of four wedges allows me to estimate a share of the variance explained by this subset of wedges.

All one-wedge economies are presented on Figures 6 - 9. Each of the figures compares the actual data (investment, output and the unemployment rate) with the series generated by the model when only a single realized wedge series is fed into the policy functions.

As Figure 6 shows, the investment wedge does not explain any of the series. This is consistent with the intuition I provided in the previous subsection. Recall that the investment wedge is the wedge in the Euler equation. Since it is the only forward-looking equation in the model, Figure 6 implies that the model captures intertemporal decisions of the agents well.

Figure 7 presents the efficiency wedge only economy. This figure shows that the TFP fluctuations explain only part of the variation in the investment series, but they do not explain any fluctuations in either GDP or the unemployment rate. This is a striking result, because it reverses a key finding of the business cycle literature that $70 \%$ of all economic fluctuations can be attributed to changes in productivity. In the model, the ratio of real output to the real wage is almost flat, because the real wage reacts almost one-to-one to changes in productivity. In contrast, real investment is more elastic than the real wage with respect to an increase in productivity. Thus, the effect of a one-time increase in productivity is large for investment measured in wage units whereas for output it is negligible. This explains why TFP shocks explain a significant share of variation in the investment series while the explained share of output in wage units is close to zero (see Figure 7). 

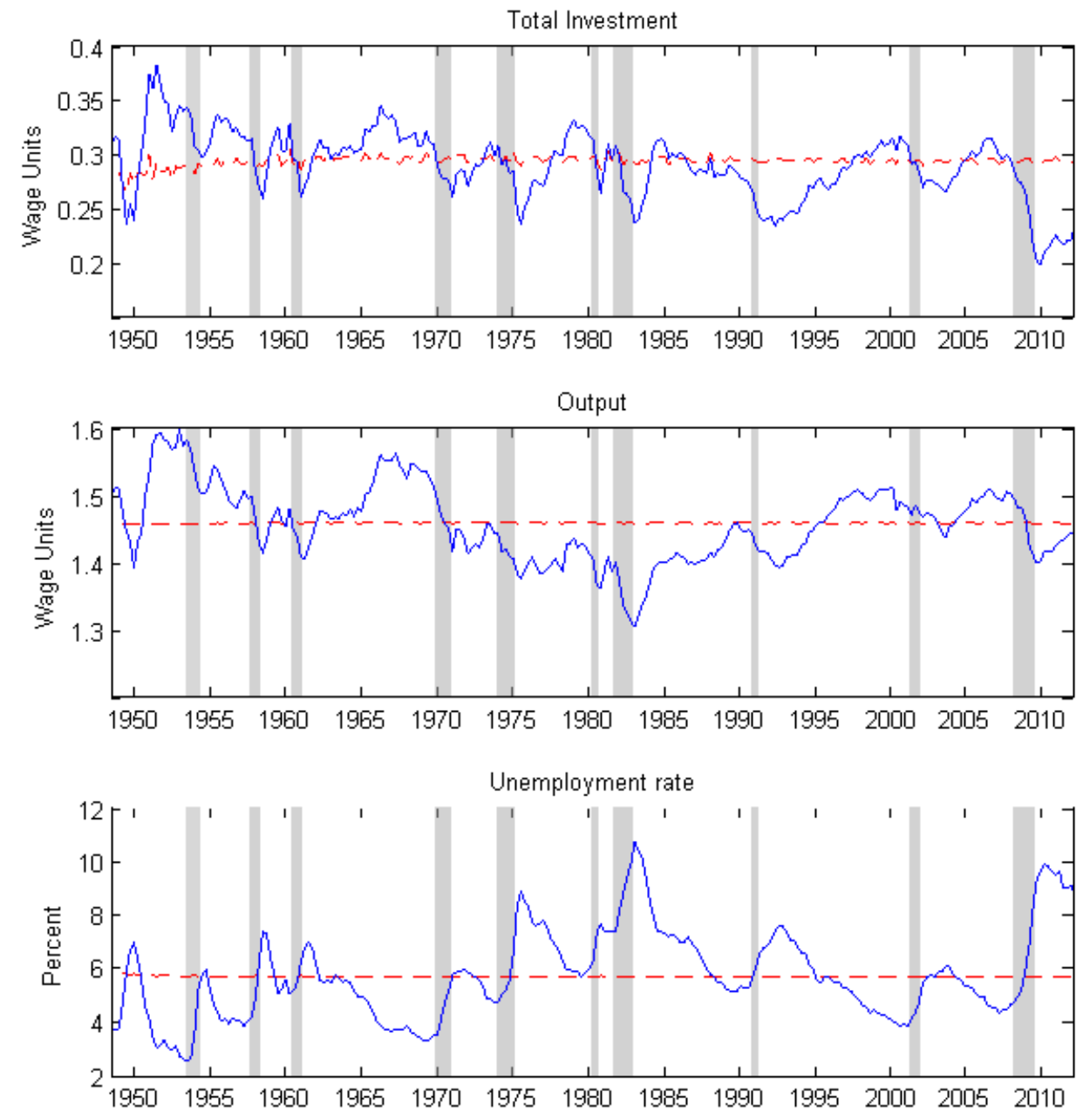

Figure 6. Investment wedge only economy. Dashed lines represent the series implied by the model. Solid lines represent the actual series.

Figure 8 implies that the labor demand wedge explains a substantial share of output, but does not explain any variation in the unemployment rate or the investment series. This reflects the fact that the labor demand wedge is highly correlated with output (see the first half of Table $3)$. Recall, that this high correlation follows from the fact that the labor income share is countercyclical. In contrast, the Cobb-Douglas production function imposes a constant labor share. I assumed a constant labor share in the prototype economy to make my results comparable with those obtained by Chari, Kehoe, and McGrattan (2007). A possible solution to the autocorrelated residual in the labor demand equation is to assume a CES production function. 

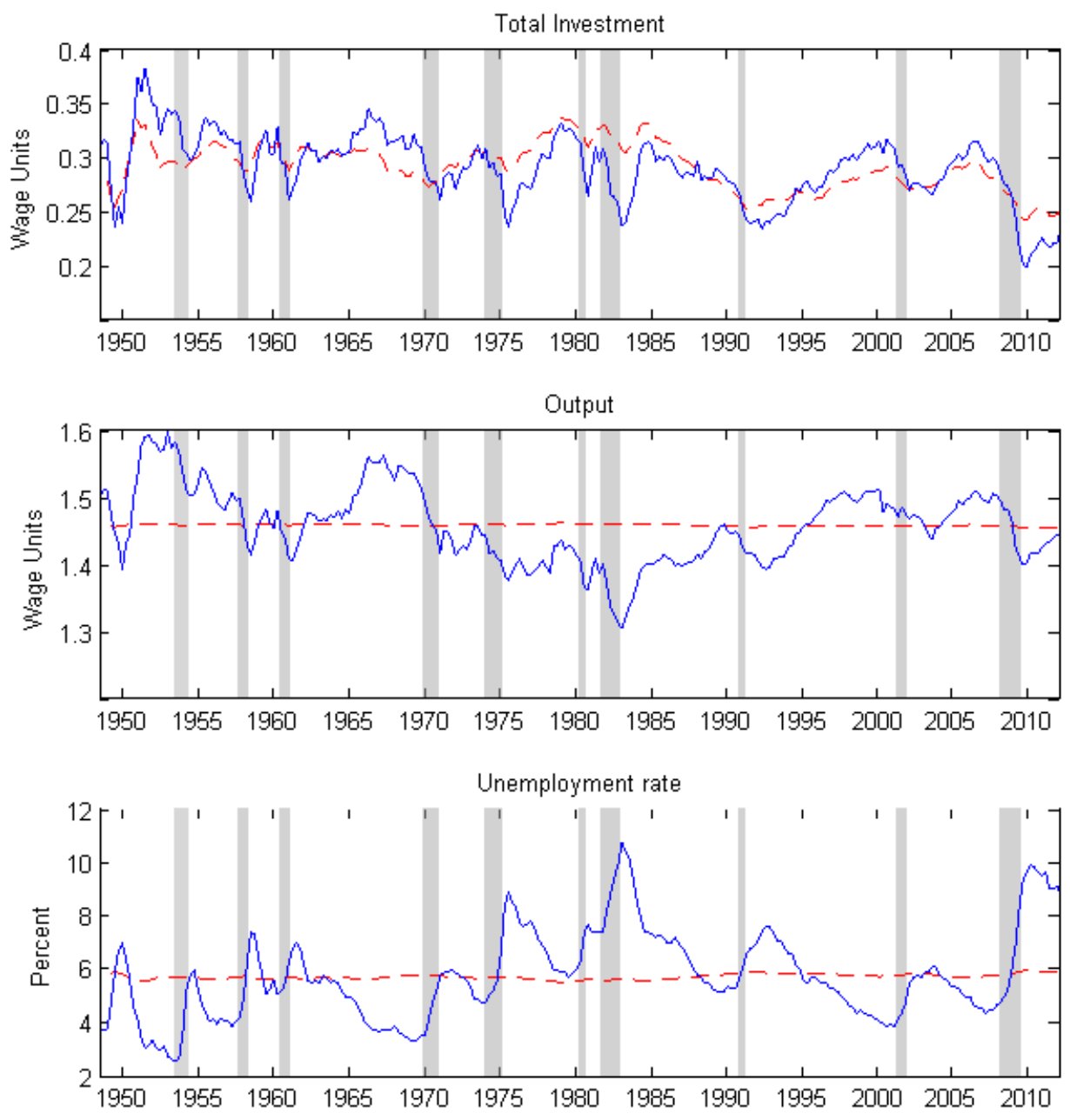

Figure 7. Efficiency wedge only economy. Dashed lines represent the series implied by the model. Solid lines represent the actual series.

This would make the labor income share a function of output and the current employment level. ${ }^{18}$

Finally, Figure 9 implies that the labor supply wedge explains almost all of the variation in the unemployment rate and significant shares of the variation in the output and the investment series. As in Chari, Kehoe, and McGrattan (2007) I find that the labor wedge explains a significant portion of variation in investment. In contrast to Chari, Kehoe, and McGrattan (2007) I find that it is the labor supply wedge that explains an overwhelming share of variation in the

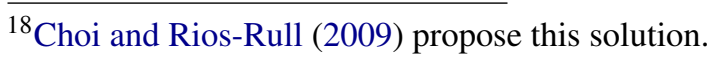



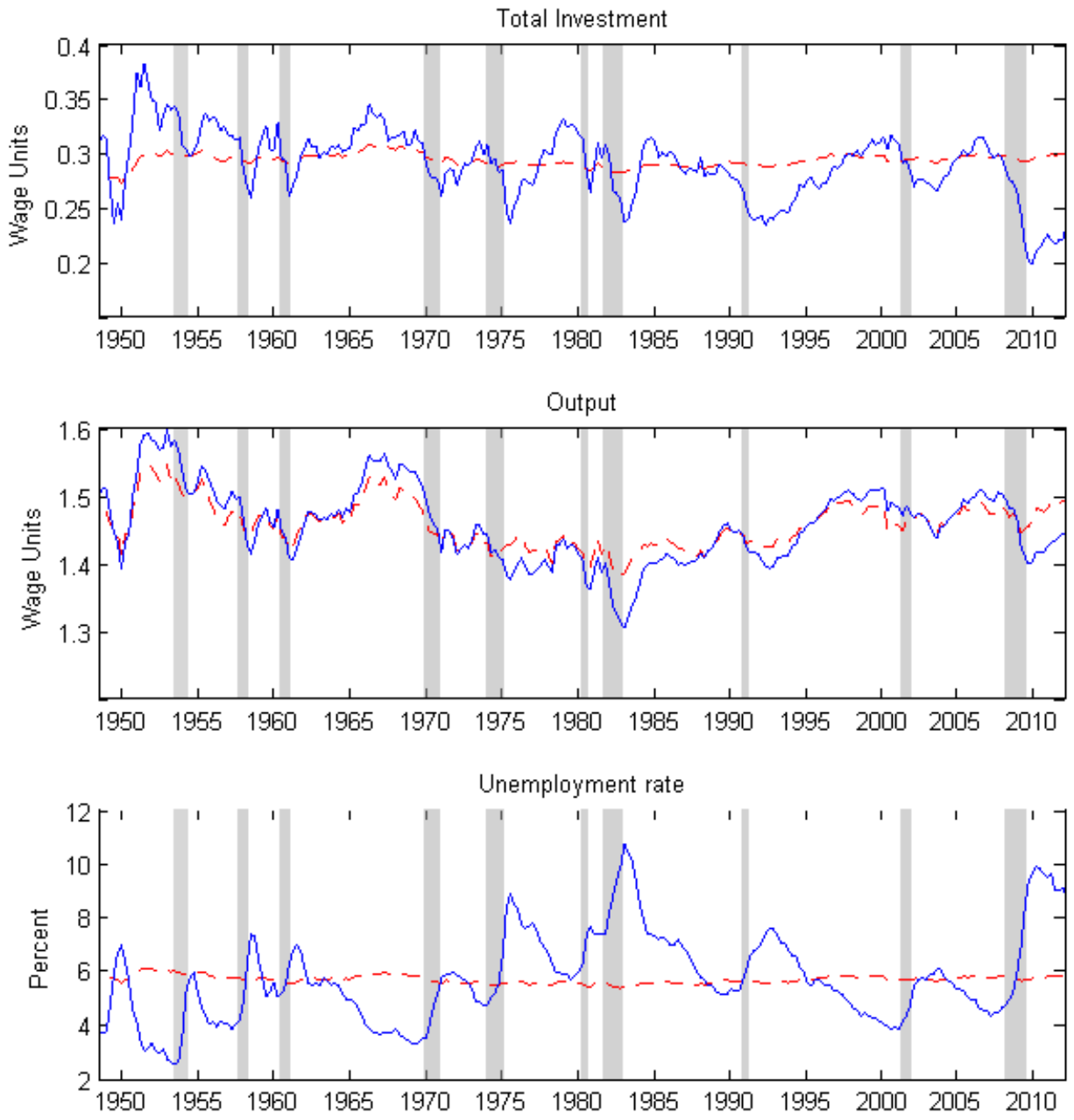

Figure 8. Labor demand wedge only economy. Dashed lines represent the series implied by the model. Solid lines represent the actual series.

unemployment rate relative to the share of variation explained by the TFP fluctuations and the labor demand wedge.

Table 4 summarizes fractions of explained variance for economies with different subsets of wedges included. I include the investment wedge in all of the economies because it explains a negligible fraction of each series. It follows from the first three rows of Table 4 that the efficiency wedge explains approximately $50 \%$ of the variation in the investment series, the labor demand wedge explains $37 \%$ of variation in the output and $5 \%$ of variation in the investment series. The rest of the variation in the data is explained by the labor supply wedge. Note that 

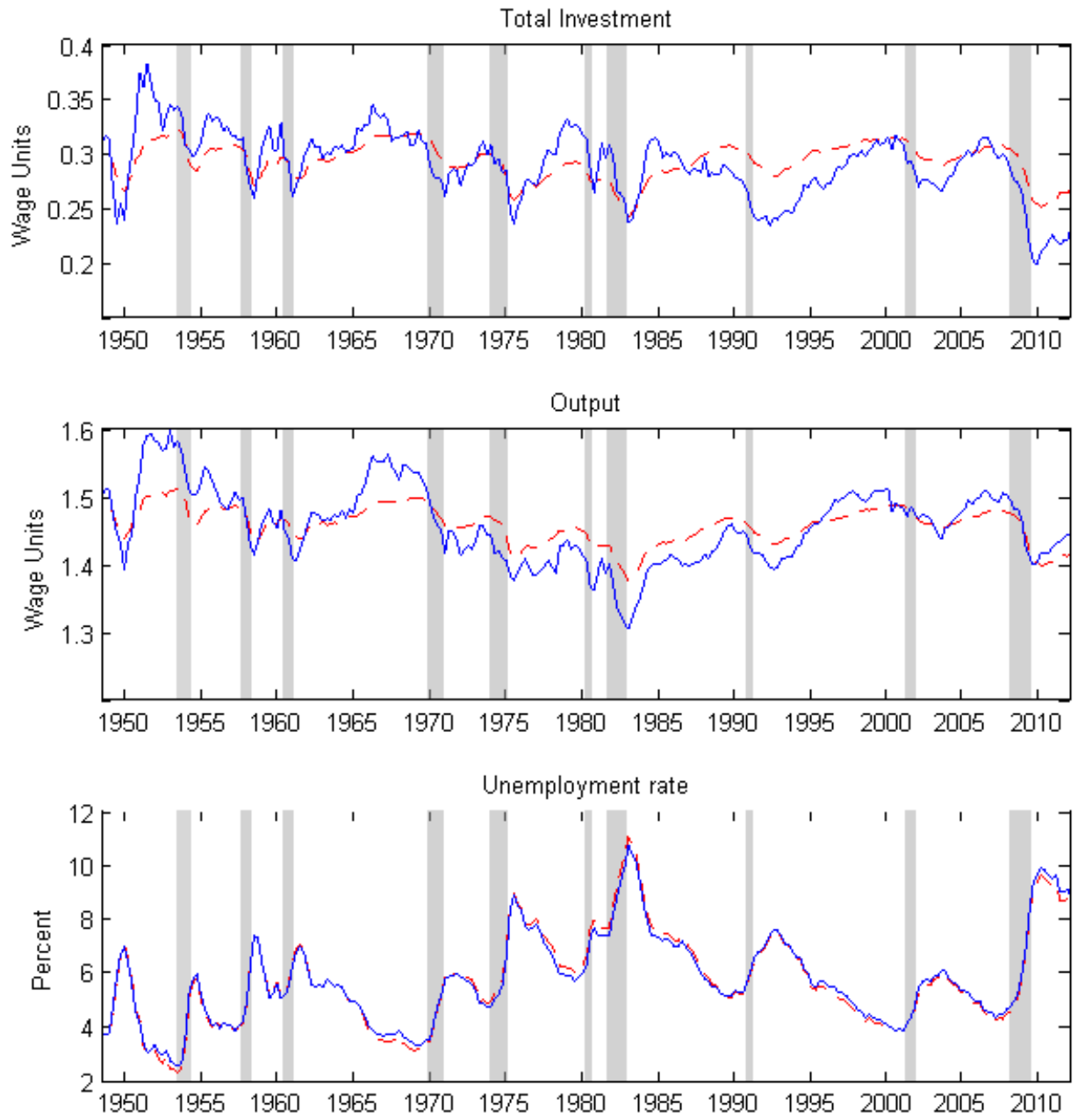

Figure 9. Labor supply wedge only economy. Dashed lines represent the series implied by the model. Solid lines represent the actual series..

all wedges except the labor supply wedge together explain a negligible share of the variation in the unemployment rate. ${ }^{19}$

\footnotetext{
${ }^{19}$ The number higher than 100 in Table 4 means that labor supply wedge generates unemployment rate that is more volatile than in the data.
} 


\begin{tabular}{cccc} 
& \multicolumn{3}{c}{ Percent of variation explained in log } \\
\cline { 2 - 4 } Wedges included $^{*}$ & Output & Unemployment rate & Investment \\
\hline \hline Efficiency* & 0.20 & 1.32 & 49.45 \\
Labor demand (LD)* $^{*}$ & 36.77 & 1.65 & 4.91 \\
Labor supply (LS) $^{*}$ & 23.67 & 114.23 & 30.32 \\
Efficiency and LD* $^{*}$ & 36.58 & 2.12 & 50.94 \\
LS and LD* & 100.04 & 98.36 & 45.56 \\
\hline
\end{tabular}

*Investment wedge always included

Table 4. Share of variation in output and unemployment explained by different wedges, defined as $\frac{\operatorname{var}\left(\log \left(x_{t}^{\text {model }}\right)\right)}{\operatorname{var}\left(\log \left(x_{t}^{\text {obs }}\right)\right)} \cdot 100 \%$

\section{Discussion of The Results}

I discuss the following two questions in this section. Why does the standard RBC model fail to match the data measured in wage units? And why does it make sense to look not just at hours worked when studying business cycle fluctuations but rather at the unemployment rate?

The failure to match the data is not surprising, since the RBC model was constructed to match much less volatile data (deviations from the HP-trend.) To put HP-detrended GDP in perspective, Figure 10 presents three series: the demeaned logarithm of GDP in wage units, the HP cyclical component and the residual from a linear trend. The y-axis plots logarithmic deviations from trend (linear and HP-trends for series 2 and 3 ) and the mean (for GDP in wage units). This figure shows that the HP-cyclical component is the least volatile of the three series. Its standard deviation is 2 times less than that of GDP in wage units and 4 times less than that of the linear trend residual.

While this is useful to study the HP cyclical component when economic fluctuations are relatively small, it eliminates a significant fraction of potentially interesting business cycle variation can explain persistence in the unemployment rate.

How is variation in the employment rate related to the variation in hours worked? How would using hours worked change the results of the accounting procedure? In the RBC literature hours worked per person are defined in the following way:

$$
\text { HoursWorked }_{t}=\frac{h_{t} \cdot L_{t}}{P_{t}}
$$




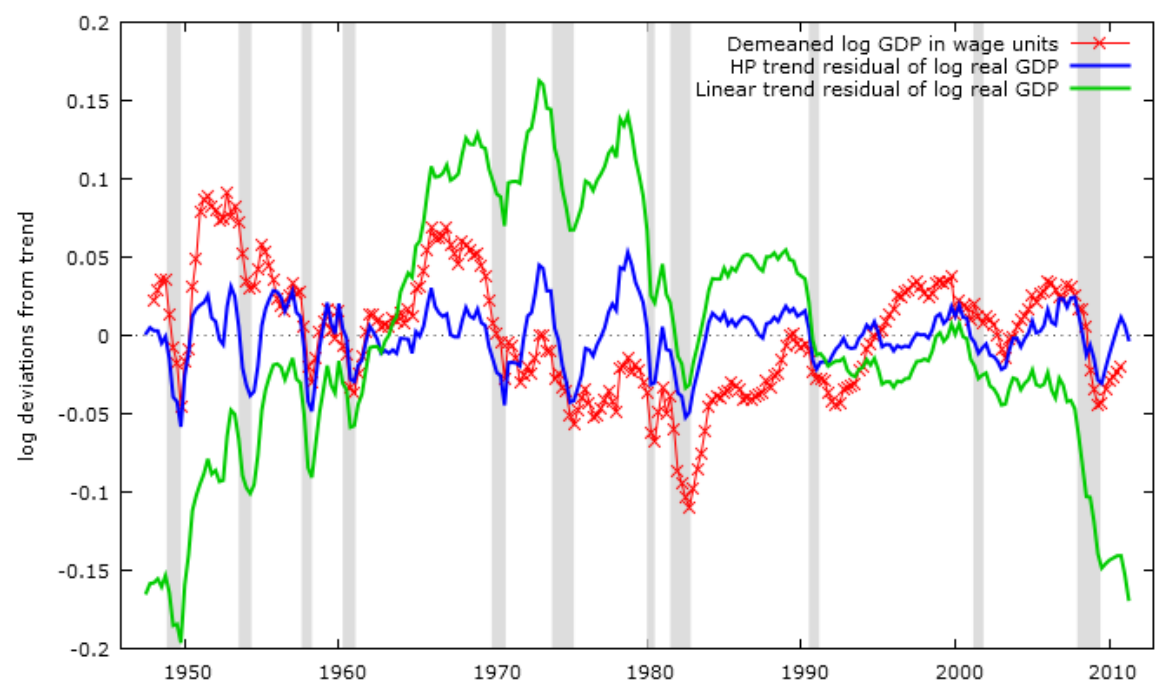

Figure 10. U.S. GDP detrended in three different ways.

where $h_{t}$ are the average number of hours worked per week, $L_{t}$ is the number of people employed and $P_{t}$ is noninstitutional population aged 16 to 64 . Dividing both the numerator and denominator of the expression above by a measure of civilian labor force $N_{t}$ one can decompose it into three terms.

$$
\text { HoursWorked }_{t}=h_{t} \cdot \frac{L_{t}}{N_{t}} \cdot \frac{N_{t}}{P_{t}}=h_{t} \cdot\left(1-u_{t}\right) \cdot \frac{N_{t}}{P_{t}}
$$

where the unemployment rate is $u_{t}=1-\frac{L_{t}}{N_{t}}$. The third component in this expression, $\frac{N_{t}}{P_{t}}$, is the labor force participation rate. I report the first and third components in Figure 11. Average hours per week, $h_{t}$, are depicted on the left. ${ }^{20}$ These series do not exhibit much movement at business cycle frequencies with the possible exception of the Great Recession when hours dropped substantially. Similarly, the labor force participation rate, $\frac{N_{t}}{P_{t}}$ (see Figure 11, right) is acyclical except the Great Recession.

Thus, almost all of the variation in the standard measure of hours worked at business cycle frequencies has to come from the employment rate, $1-u_{t} \cdot{ }^{21}$ Figure 12 supports this argument. It plots series of normalized hours worked (defined as in (31)) against the employment

\footnotetext{
20 These series come from Cociuba, Prescott, and Ueberfelt (2012).

21 Tasci and Pescatori (2011) provide another reason to focus on the employment rate, rather than hours worked. The paper shows that by focusing on hours worked, one can falsely overstate the importance of the labor wedge in explaining business cycles.
} 
(a) Average hours per week

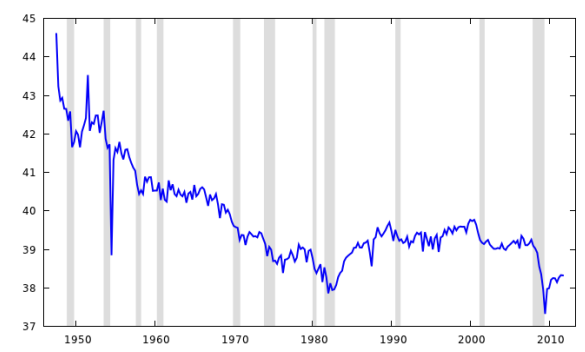

(b) Labor force participation rate (percent)

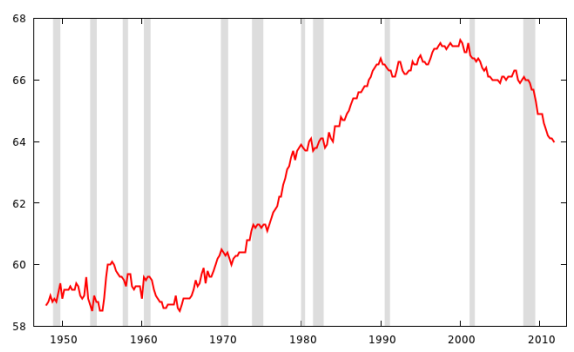

Figure 11. Components of the standard measure of hours worked.

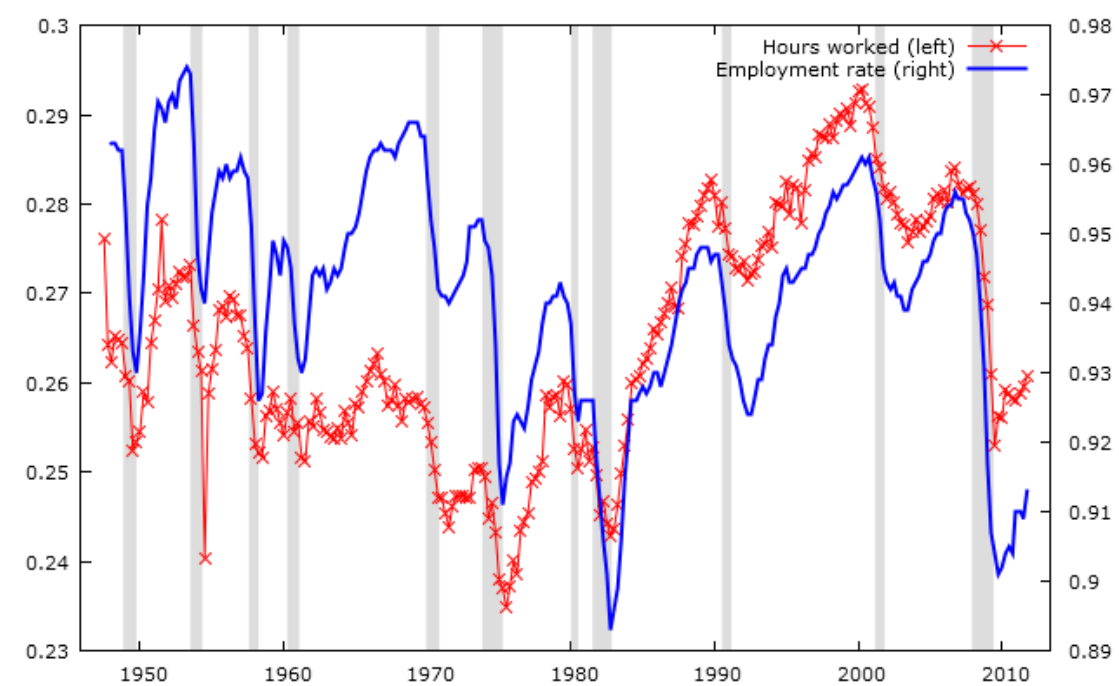

Figure 12. Normalized series of hours worked (left scale) and the employment rate (right scale)

rate. $^{22}$ The series in Figure 12 are highly correlated, although hours worked are a noisier measure of employment. This is especially true for the period before 1976 for which the data sources used to derive the hours worked series are different and potentially less reliable. ${ }^{23}$

Given all the evidence above, if one were still to use hours worked as a measure of employment instead of the employment rate, why would not it improve performance of the model? The fact that the means of the two series are different is irrelevant, because it will only affect the estimate of $\psi$ in the labor supply (Equation (20)). The standard deviations of these series are very close: 0.016 for the employment rate vs 0.013 for the hours worked. This means

\footnotetext{
${ }^{22}$ The series on hours worked come from the same paper: Cociuba, Prescott, and Ueberfelt (2012).

${ }^{23}$ The Chow test confirms a structural break in the relationship between normalized hours series and the unemployment rate in 1976 at the $1 \%$ confidence level.
} 
that explaining hours worked series is not going to be easier for the model. Moreover, using hours worked instead of the employment rate will adversely affect the labor demand wedge, because an analog of Equation (5) does not exist for GDP in wage units and hours worked.

To evaluate these arguments formally, I repeat the estimation procedure with the same priors for all parameters, using hours worked as a measure of employment instead of the employment rate. I obtain unrealistic and unstable posterior estimates of all of the parameters of the model. Logarithm of the likelihood function is almost two times as less than the benchmark estimation (1945 versus 1083). Additionally, the standard deviation of the labor demand wedge is more than 40 times larger than in the benchmark case.

To summarize, most of the variation in hours worked comes from the variation in the unemployment rate. Using hours worked as a measure of employment does not improve performance of the model.

\section{Conclusion}

This paper evaluates performance of the standard real business cycle model using aggregate U.S. data in wage units. The main advantage of using wage units instead of a conventional approach (such as the HP filter or a band-pass filter) is that this approach preserves medium-term fluctuations across macroeconomic series. As I show in the paper, these common medium-term fluctuations are an important component of the business cycle and should not be ignored.

I find that the standard model has trouble explaining the data in wage units. In particular, I show that, first, productivity innovations explain only 50\% of fluctuations in the investment series and virtually none of the fluctuations in GDP and unemployment. This contradicts the well-known stylized fact that productivity innovations can explain more than $70 \%$ of business cycle fluctuations. The failure of the RBC model to explain the data follows from the fact that GDP measured in wage units is twice as volatile as GDP filtered using the conventional approach. In other words, filtering data using the HP filter masks the problem by removing a major fraction of data volatility. This finding is consistent with the studies that looked at "medium-term business cycles" - the outcome of a band-pass filter. ${ }^{24}$

Second, I find that the smoothed labor demand wedge (which is equivalent to the labor income share) is strongly countercyclical. This as an argument in favor of an aggregate produc-

${ }^{24}$ See Comin and Gertler (2006)) 
tion function with a varying labor share (such as a CES production function) and against a Cobb-Douglas specification. This finding is consistent with Choi and Rios-Rull (2009); RiosRull and Santaeulalia-Llopis (2010).

Finally, data in wage units facilitates disaggregation of the labor wedge into the labor demand and the labor supply wedges. I show that the main problem is with the labor supply wedge, which accounts for $99 \%$ of the variation in the unemployment rate. Intuitively, the real business cycle model fits the data badly because the assumption that households are on their labor supply equation is flawed. Specifically, the observed data suggests that high spells of unemployment are far from efficient allocation - the equilibrium in the RBC model. This finding supports the assumptions made in the incomplete labor market literature (see Farmer (2010, 2011); Farmer and Plotnikov (2012); Kocherlakota (2012)). This finding is also consistent with Justiniano, Primiceri, and Tambalotti (2010) who find that labor supply shocks are important at low frequencies. 


\section{REFERENCES}

Adjemian, Stephane, Houtan Bastani, Michel Juillard, Ferhat Mihoubi, George Perendia, Marco Ratto, and Sebastien Villemot, 2011, “Dynare: Reference Manual, Version 4," Dynare Working Papers, CEPREMAP, Vol. 1.

An, Sungbae, and Frank Schorfheide, 2007, "Bayesian analysis of DSGE models," Econometric Reviews, Vol. 6, pp. 113-172.

Ball, Laurence, 2014, "Long-Term Damage from The Great Recession in OECD countries," NBER Working Paper 20185.

Basu, Kaushik, 2009, “A Simple Model of the Financial Crisis of 2007-9 with Implications for the Design of a Stimulus Package," CAE Working Paper 09-11.

Baxter, Marianne, and Robert G. King, 1999, "Measuring Business Cycles: Approximate Band-Pass Filters for Economic Time Series," Review of Economics and Statistics, Vol. 81, No. November, pp. 575-593.

Benes, Jaromir, Kevin Clinton, Roberto Garcia-Saltos, Marianne Johnson, Douglas Laxton, Manchev Petar, and Troy Matheson, 2010, "Estimating Potential Output with a Multivariate Filter,' IMF Working Paper 10/285.

Canova, Fabio, 2014, "Bridging the DSGE Models and the Raw Data," Journal of Monetary Economics, 67, 1-15, 2014.

Chari, V. V., Patrick Kehoe, and Ellen McGrattan, 2007, "Business Cycle Accounting," Econometrica, Vol. 75, No. 3, pp. 781-836.

Choi, Sekyu, and Jose-Víctor Rios-Rull, 2009, "Understanding the Dynamics of Labor Share: The Role of Noncompetitive Factor Prices," Annales d'Economie et Statistique, Vol. No. 95/96.

Cociuba, Simona, Edward Prescott, and Alexander Ueberfelt, 2012, "U.S. Hours and Productivity Behavior Using CPS Hours Worked Data: 1947-III to 2011-IV," .

Cole, Harold L., and Lee E. Ohanian, 2004, "New Deal Policies and the Persistence of the Great Depression: A General Equilibrium Analysis," Journal of Political Economy, Vol. 112, No. 4, pp. 779-816.

Comin, Diego, and Mark Gertler, 2006, "Medium Term Business Cycles," American Economics Association, Vol. 96, No. 3, pp. 526-531.

Cowen, Tyler, 2012, “Multiple equilibria?” Marginal Revolution Blog, Vol. http://marginalrevolution.com/marginalrevolution/2012/10/multiple-equilibria.html.

Farmer, Roger E. A., 2010, Expectations, Employment and Prices (Oxford University Press).

—_, 2011, “Confidence, Crashes and Animal Spirits," Economic Journal.

Farmer, Roger E A, 2012, "The stock market crash of 2008 caused the Great Recession: Theory and evidence," Journal of Economic Dynamics \& Control, Vol. 36, pp. 693-707. 
Farmer, Roger E. A., and Dmitry Plotnikov, 2012, "Does Fiscal Policy Matter? Blinder and Solow Revisited," Macroeconomic Dynamics, pp. 1-18.

Gomme, Paul, and Peter C. Rupert, 2004, “Measuring Labor's Share of Income," Federal Reserve Bank of Cleveland, Policy Discussion Papers, Vol. 7.

Guerrazzi, Marco, 2010, "Stochastic Dynamic Matching in the Old Keynesian Economics: A Rationale for Shimer's Puzzle," Discussion Paper del Dipartimento di Scienze Economiche - Univertsita di Pisa, No. 95.

Haltmaier, Jane, 2012, “Do Recessions Affect Potential Output?” Board of Governors of the Federal Reserve System, International Finance Discussion Papers, Number 1066.

Heathcote, Jonathan, and Fabrizio Perri, 2012, "Wealth and Volatility," Bocconi University working paper.

IMF, 2009, "What is the Damage? Medium-Term Output Dynamics after Financial Crises," World Economic Outlook.

— 2017 , "Understnading the Downward Trend in Labor Income Shares," World Economic Outlook.

Jacobson, Margaret, and Filippo Occhino, 2012, "Labor's Declining Share of Income and Rising Inequality," http://www.clevelandfed.org/research/commentary/2012/2012-13.cfm.

Justiniano, Alejandro, Giorgio E. Primiceri, and Andrea Tambalotti, 2010, "Investment Shocks and Business Cycles,” Journal of Monetary Economics, Vol. 57, pp. 132-145.

Kaplan, Greg, and Guido Menzio, 2012, "Shopping Externalities and Self-Fulfilling Unemployment Fluctuations," Princeton working paper.

Kashiwagi, Masanori, 2012, "Sunspots and Self-Fulfilling Beliefs in the U.S. Housing Market," Working paper.

Kocherlakota, Narayana, 2012, "Incomplete Labor Markets," Research Papers of Minneapolis Federal Reserve.

Miao, Jianjun, Pengfei Wang, and Zhiwei Xu, 2012, "A Bayesian DSGE Model of Stock Market Bubbles and Business Cycles," Working paper.

Rios-Rull, Jose-Victor, and Raul Santaeulalia-Llopis, 2010, "Redistributive Shocks and Productivity Shocks,” Journal of Monetary Economics, Vol. 57(8), pp. 931-948.

Sims, Christopher A., 2001, "Solving Linear Rational Expectations Models," Journal of Computational Economics, Vol. 20, No. 1-2, pp. 1-20.

Tasci, M., and Andrea Pescatori, 2011, "Search Frictions and the Labor Wedge," IMF Working Paper 11/117. 